\title{
Música para uma exposição cartográfica
}

\begin{abstract}
Anna Maria Kieffer ${ }^{1}$
RESUMO: $\bigcirc$ artigo explora o uso da documentação histórica para composição das duas trilhas musicais que sonorizaram a exposição Cartografia de uma História: São Paulo Colonial, mapas e relatos, exibida no Museu Paulista. A primeira trilha, destinada ao vídeo instalado na sala cujo tema foi América: a quarta parte; a segunda, instalada na sala dedicada à cartografia do sertão e aos relatos da exploração do interior da capitania de São Paulo.

PALAVRAS-CHAVE: Música eletroacústica e espaço. Grupo de Mogi. Testamentos bandeiristas. Violas e cantigas. Benzimentos. Música Kaiapó e Bororo.

ABSTRACT: This paper explores the use of historical documentation as a basis for the composition of two musical scores for an exhibition titled Cartography of a history: colonial São Paulo, maps and accounts, staged at Museu Paulista. The first one was written for a video shown in an exhibition hall dedicated to the topic America: the fourth part; the second score was played in another gallery, serving as a sound track for an exhibition of maps of Brazil's backcountry and accounts related to the exploration of the interior of the captaincy of São Paulo.

KEYWORDS: Electroacoustic music and space. Mogi Group. Bandeiristas'Will. Viols and ballads. Blessings. Kaiapó and Bororo music.

"Ondas do mare levado

Se vistes o meu amado E ai, Deus! Se verrá cedo?" 2

Martin Codax, Cantiga I

"Le voyage des bandeirantes de São Paulo, sur le fleuve Tiêté, au 18 ième siècle et ce voyage dans l'espace historique (voyage mental par excellence) s'apprête bien à accueillir cette musique d'autant plus que ce voyage imaginaire sur le fleuve llui aussi comparable à un flux continu interrompu seulement par le bruit de la faune, de la flore et des tribus indigènes vivant au bord du fleuve) crée une correspondance coulante avec la musique."
\end{abstract}

Leo Kupper, 4 février 2006
1. Anna Maria Kieffer é cantora e pesquisadora de música, responsável pela série Memória Musical Brasileira, editada pela Akron, em São Paulo, entre 1994 e 2004, que inclui os seguintes CDs e CDs-livros: Teatro do Descobrimento; Marilia de Dirceu; Viagem pelo Brasil; 1900: A Virada do Século; Alberto Nepomuceno: Canções, Mel Nacional e Cancioneiro da Imigração. Também participa, como intérprete e colaboradora, em CDs e CDs-livros que abordam criações contemporâneas, tais como: Jocy de Oliveira, Fata Morgana. São Paulo: Eldorado, 1990; Conrado Silva e Haroldo de Campos, Espaços Habitados. Brasília: Estúdio M, 1994; Daniel Teruggi, Fugitives Voix, em The Shining Space. London: Sargasso, 2000; Guilherme Vaz, A Pedra, em O Anjo sobre o Verde. Goiânia: OMGR, 2001; e Leo Kupper, Ways of the Voice. New York: Pogus, 1999; reeditado por Bruxelas: SRSEA; São Paulo: Akron, 2004. E-mail: <akron3@terra.com.br>.

2. Ver Manuel Pedro Ferreira (1986, p. 129).

3. Cf. O. Alvarenga (1960, p. 64).

4. Cf. M. Q. Gavaldá (1971, p. 81 .

5. Recolhida por Mário de 
Andrade, em João Pessoa. Cf. M. de Andrade (1959, p. 215).

6. Ibidem.

Inúmeras são as referências ao mar e à navegação na literatura e na música ibéricas, desde o período medieval, referências estas que se amiudarão, à medida que as explorações marítimas de longa distância vão se tornando mais frequentes, a ponto de se fixarem em formas poético-musicais tradicionais ainda celebradas, inclusive no Brasil, como romances e autos populares que sintetizam a aventura dos descobrimentos.

No caso português e luso-brasileiro, particularmente, podemos citar o Conde da Armada, o Corsário da Índia e, sobretudo, a Nau Catarineta, inserida na Marujada, dança-dramática que reproduz em detalhes uma viagem marítima, descrevendo o içar das velas, a partida, a saudade dos que ficam, o temor dos que vão, o comportamento dos marinheiros, a falta de alimento em meio à travessia, os motins, os ataques piratas, as calmarias, as tempestades "no mar alto", a luta entre entidades superiores do mal e do bem, prevalecendo a vitória dessas últimas.

Da mesma forma que a Marujada, a Cheganças de Mouros aborda episódios marítimos e pode-se notar, no encadeamento das diferentes jornadas de ambas as representações, o entusiasmo da viagem, a curiosidade pelo desconhecido, a ânsia de avançar:

Lá se vai u anau atirando

Pelo má largando as vela,

Deus u leve, Deus o traga,

Deus u bot'im Porto Alegre

Lá se vai o anau atirando

Cum u seu brilhante dia

Deus u leve, Deus o traga

Par'u porto da Baía!

Essas mesmas naus, de velas enfunadas, povoam os mares dos mapas que, primeiramente, mostram os contornos da América e do Brasil, assim como personagens mitológicos, monstros marinhos e iconografia da Virgem, Senhora protetora dos navegantes, já invocada, em música, no século XV:

Ay, Santa Maria, valedme,

Senhora, esperança mia! ${ }^{4}$

invocação que aparece repetida em trecho de Chegança de Marujos ${ }^{5}$, na qual a Virgem, além de protetora, é também o rumo, o Norte indicado nas rosas dos ventos presentes em todos os mapas do período:

Clara Istrela do Norte,

Valha-me a Virge Maria! ${ }^{6}$

Ao ser convidada para participar com a trilha sonora da exposição 
Cartografia de uma história - São Paulo colonial: mapas e relatos, realizada no Museu Paulista e curada por Íris Kantor e Beatriz Siqueira Bueno, sob coordenação de Vera Lúcia Amaral Ferlini, pensei primeiramente em utilizar um sistema de referências que fizesse interagir história, iconografia e música tradicional. Mas, no decorrer das reuniões preparatórias, e em contato com os demais membros que participariam dessa grande experiência, foi definido que: 1) a exposição não seria montada apenas a partir da cartografia de época. Haveria, como houve, uma multiplicidade de leituras, inclusive as obtidas através de alta tecnologia (imagens de satélite), fornecidas pelo Instituto Nacional de Pesquisas Espaciais (Inpe); 2) o corpo da exposição incluiria um vídeo, a ser realizado por Paulo Pastorelo e João Sodré; 3) as trilhas seriam, portanto, duas: a primeira, que serviria ao vídeo localizado na sala 14 (América: a quarta parte), mas que deveria sonorizar também as salas vizinhas e, a segunda, que integraria o módulo Caminhos e caminhantes: as vivências do sertão, na sala 297 .

A partir das primeiras amostras do vídeo, percebi que a câmera trabalhava com movimentos que também traduziam uma viagem, inclusive no tocante a efeitos especiais, realizados em computador, que mostrariam a transformações dos próprios mapas e de seu significado, entre fins do século XV e meados do XIX.

A ideia original, pois, de uma música baseada na tradição popular, não faria mais sentido, nesse caso (poderia fazê-lo, em parte, em se tratando da segunda trilha) e pensei em algo que pudesse ser mais adequado, realizado com sons gerados tecnologicamente e que se acordassem melhor com as imagens do Inpe. Do mesmo modo, procurei algo que traduzisse uma estética mais abstrata, mas cuja pulsação, ritmo e duração também induzissem a uma viagem não mais marítima, mas sideral, trabalhando conceitos de som e espaço, uma vez que os cartógrafos, para desenhar a terra, tiveram que olhar o céu.

Esses conceitos estão, todos eles, presentes em Aerosons ${ }^{8}$, obra eletroacústica do compositor Leo Kupper, criador e diretor do Studio de Recherches et de Stucturations Électronique-Auditives, em Bruxelas. Composta em 1982, objetivando uma viagem ao Brasil, foi apresentada em primeira audição mundial, ao ar livre, em concerto realizado no Parque Lage, no Rio de Janeiro, com minha participação ao vivo. Essa participação, eminentemente vocal e improvisatória, fazia sentido, uma vez que, na peça original, sons humanos realizados com o aparelho fonador (roncos, grunhidos e sons aspirados) se juntam a sons eletrônicos. Nas palavras de Leo Kupper:

\footnotetext{
A peça Aerosons, que significa sons aéreos, lembra, pelo seu continuum, sonoridades que se ouvem em vôos intercontinentais. Os sons aéreos deixam o solo, se elevam e fluem no ar, na forma de aerosons.

Sua forma compositiva (a, b, c), com sua introdução, desenvolvimento e saída, se relaciona à visitação de um local santo e é específica dos processos de meditação. Os ruídos fonéticos e eletrônicos pontuam o fluxo na introdução e na saída. Ao centro da composição, um longo crepitar eletrônico acompanha melodias de caráter místico. A forma é claramente compreen-
}

7. Ficha técnica das trilhas sonoras: Leo Kupper (comp.), Aerosons. Bruxelas: Studio de Recerches et de Structurations Électroniques-Auditives, 1982; Anna Maria Kieffer, $\mathrm{Ca}$ minhos do Sertão, com participação de: Rodolfo Nanni, narrador; Amin Taissun, barítono; Anna Maria Kieffer, voz (narração e canto); Leo Kupper, ruídos fonatórios; Gisela Nogueira, viola de arame e arranjos; Anônimo, Música Guarani, com participação de integrantes da aldeia Tenondé Porã, São Paulo; Anônimo, Música Bororo, sem indicação de aldeia; Anônimo, Música Kaiapó, com participação de integrantes das aldeias de Kretire e Jarina, Xingu. Gravação, edição e mixagem: Cia. do Gato. São Paulo, Brasil, 2004. Concepção geral e direção musical: Anna Maria Kieffer Agradecimentos: Julio de Paula e Jonas Soares de Souza.

8. Disponível na versão on-line deste artigo na Coleção SciELO Brasil. 
9. Depoimento à autora. Cf. Leo Kupper (1982).

10. Disponível na versão on-line deste artigo na Coleção SciELO Brasil. sível e diz respeito àqueles viajantes que, corajosamente, se aventuraram em busca do desconhecido, tão curiosos por um mundo novo quanto, ainda hoje, o somos?.

A obra foi usada em sua forma original e, de tal forma se encaixou aos conceitos da curadoria da exposição e às ideias de Paulo Pastorelo e João Sodré, que optamos por utilizá-la por inteiro, servindo de guia para a edição, a duração e o ritmo do vídeo.

A segunda trilha ${ }^{10}$ foi pensada como uma ambientação sonora para a sala Vivência e quotidiano no Sertão. Nela, foram expostos quadros e objetos que abordam o cotidiano bandeirista, com especial destaque para A partida da Monção, de Almeida Júnior. No centro da sala, um fragmento de enorme canoa cavada em única tora de madeira faz menção ao Tietê e, a seu lado, o original do Diário de Navegação (Figura 1). Esse documento é apresentado com seus respectivos mapas, de autoria do sargento-mor Teotônio José Juzarte que, a 13 de abril em 1769, largava de Porto Feliz com trinta e seis embarcações e 800 pessoas em monção que desceu o Tietê, o Paraná e o lguatemi até a praça do mesmo nome.

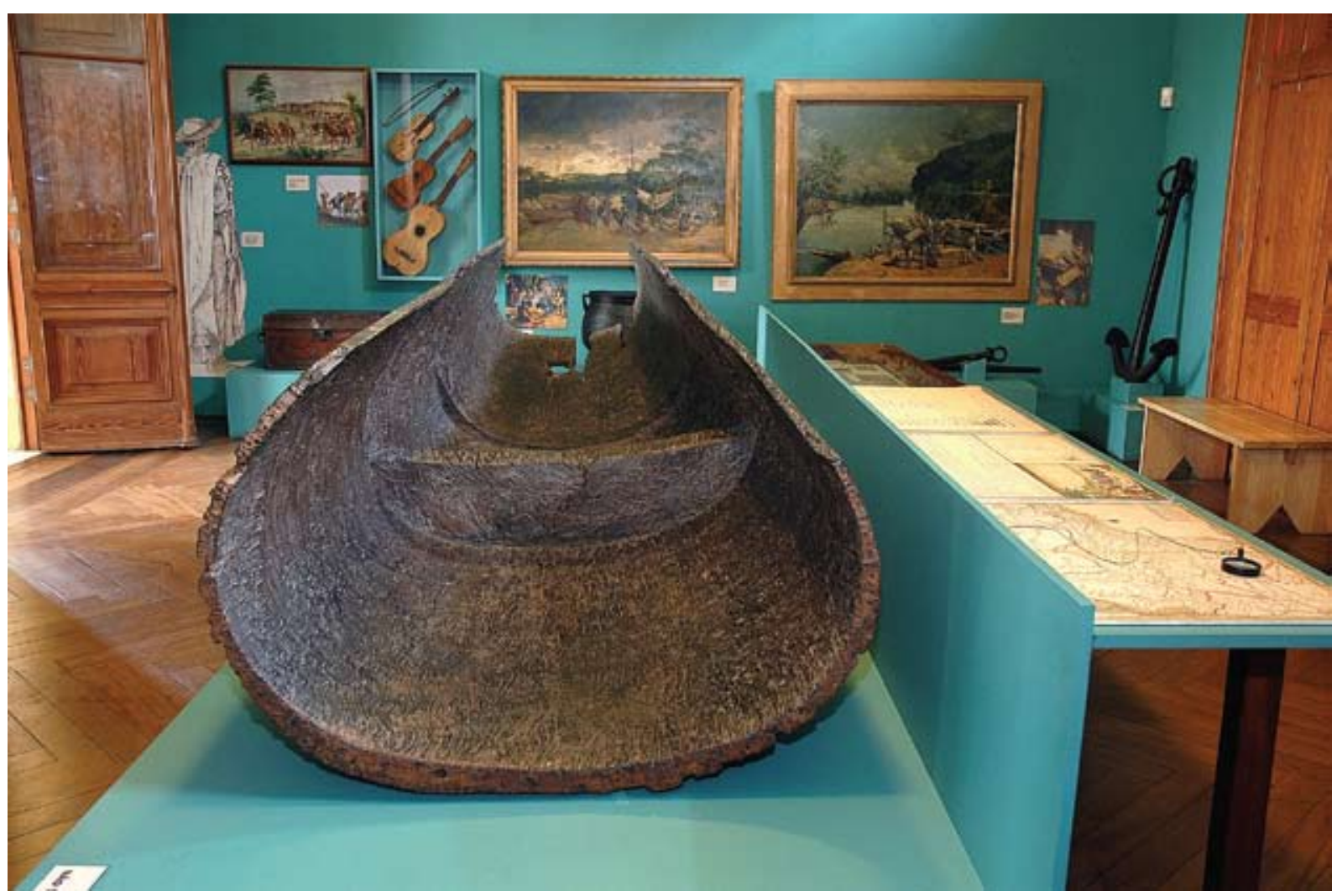

Figura 1 - Sala Vivência e quotidiano no Sertão, exposição Cartografia de uma história: São Paulo colonial, mapas e relatos. Museu Paulista, São Paulo. Fotografia de José Rosael, 2005. 
Esta viagem, de consequências trágicas, foi minuciosamente descrita por Juzarte em seu diário, constituindo material a partir do qual pude compor a trilha, concebida de forma a tornar o visitante partícipe da aventura.

Devo ressaltar que há poucas referências documentais à música praticada, nesse período, na região de São Paulo e os únicos documentos musicais conhecidos, datados da primeira metade do século XVIII, integram a coleção de partituras dos compositores que compõem o chamado Grupo de Mogi. Essas partituras, encontradas por Jaelson Trindade, em Mogi das Cruzes, serviam de estofo à encadernação do Livro de Foral da Vila de Mogi das Cruzes, aberto em 1748, e cuja aba se descolava. O achado repete o histórico do célebre Pergaminho de Vindel, que contém as cantigas de Martim Codax. No caso do Grupo de Mogi, são obras polifônicas, copiadas em 1730 1'.

Sabe-se, igualmente, através dos inventários bandeiristas que, na região de Piratininga, tocava-se guitarra (inventário de Catharina d'Horta, 1626), sistra (inventário de Francisco Leão, 1632) e violas (uma das quais pertencera ao bandeirante Sebastião Paes de Barros, inventário de 1688, e outra, que figura no testamento de Affonso Dias de Macedo, em 1703, explicitada como viola de pinho do reino) ${ }^{12}$. Havia, também, música para acompanhar as funções religiosas, entoadas por vozes, rabecas, baixão e, na falta de órgão ou outro instrumento de tecla, harpa ou viola.

De posse apenas desses dados, seria impossivel montar uma trilha que fosse elaborada unicamente com música de época e que preenchesse as necessidades da exposição. A opção foi montar uma viagem sonora que, seguindo - fluxo dos rios, pudesse remeter à monção chefiada e descrita por Juzarte e representasse uma viagem - símbolo de muitas realizadas no período.

Para tal, foram selecionados e gravados vários tipos de materiais sonoros: ruídos da natureza, como água, vento, chuva, sons produzidos por aves e outros animais, pequenas peças musicais do período, cantigas populares tradicionais, cantos indígenas, textos de documentos históricos, rezas populares, benzimentos. Esses materiais, devidamente tratados, editados e mixados, constituíram os elementos com os quais foi criada a composição, como será detalhado a seguir:

\section{O rio}

Som do fluxo de diferentes rios funcionam como um pedal sobre o qual vai se apoiar toda a trilha. Rios e riachos, tranquilos e turbulentos, esses sons foram combinados de forma a criar zonas de calmarias, ruídos de remos, corredeiras, pequenas quedas de água e cachoeiras.

\section{A partida}

Segundo Juzarte, antes da partida, "todas as pessoas estão confessadas
11. Para mais informações, ver J. Trindade e P. Castagna (1996).

12. Cf. A. E. Taunay (1931, p. 185-186). 
13. Cf. Jonas Soares de Souza e Miyoko Makino (2000, p. 27).

14. Idem, ibid.

15. Idem, p. 24.

16. Cf. A. M. Kieffer (2004) e sacramentadas, porque daqui para baixo não há mais igrejas, nem sacramentos"13.

Para ilustrar essa preparação espiritual - afinal havia notícia de outras, anteriores, cujo desfecho nem sempre foi o melhor, pairam sobre o rio ainda calmo, trechos falados de inventários bandeiristas:

"Temendo-me da morte e desejando por minha alma no verdadeiro caminho da salvação...."

"Por estar de caminho para o sertão buscar meu remédio e não saber a hora que hei de dar conta da minha vida...."

"Estando eu para embarcar e fazer uma viagem rio abaixo [...] encomendo a alma a Deus que a criou e à terra para que foi criada."

Em seguida, remetendo à informações de Juzarte, procede-se à bênção das canoas: "Estando tudo na forma dada, se dá o aviso ao pároco para que venha benzer essa expedição; o qual tomando sua estola e sobrepeliz com o seu sacristão se põem sobre o barranco do rio e, ajoelhados, entoam a ladainha de Nossa Senhora"14. Almeida Júnior, na tela A partida da monção, de 1897, representou uma cena semelhante, embora situada em outro contexto temporal. A cena principal do quadro figura a benção da expedição, nos instantes anteriores a sua partida (Figura 2).

Neste período, a ladainha em questão é a do Rito Tridentino, amavelmente cedida pelo musicólogo Paulo Castagna, mas, em função de sua extensão, acabei escolhend \o, como ilustração, a peça introdutória, também um hino à Virgem: Virgo parens Christi.

A trilha segue, com o remar das canoas, descrito por Juzarte:

"O modo de navegar é o seguinte: remando todos ao mesmo tempo e o proeiro que vai no bico da proa tem obrigação continuamente de meter o remo a água e dar uma pancada com o calcanhar no lugar onde pisa de sorte que este estrondo serve de compasso para que todos ao mesmo tempo metam os remos na água"15.

Este efeito rítmico é dado por um canto Guarani ${ }^{16}$, entoado em conjunto e ritmado pela percussão, introduzindo o elemento indígena, presente durante toda a viagem.

\section{Viagem pelo Tietê}

À medida que as canoas descem o rio em direção ao sertão, os cantos de pássaros tornam-se mais presentes, começando por pios de aves miúdas, aos quais foram acrescidos, aos poucos, gritos de anhumas, lontras (ariranhas) e a recriação do bater de dentes dos porcos-do-mato, animais citados por Juzarte, enquanto uma voz feminina reza um pai-nosso popular: 


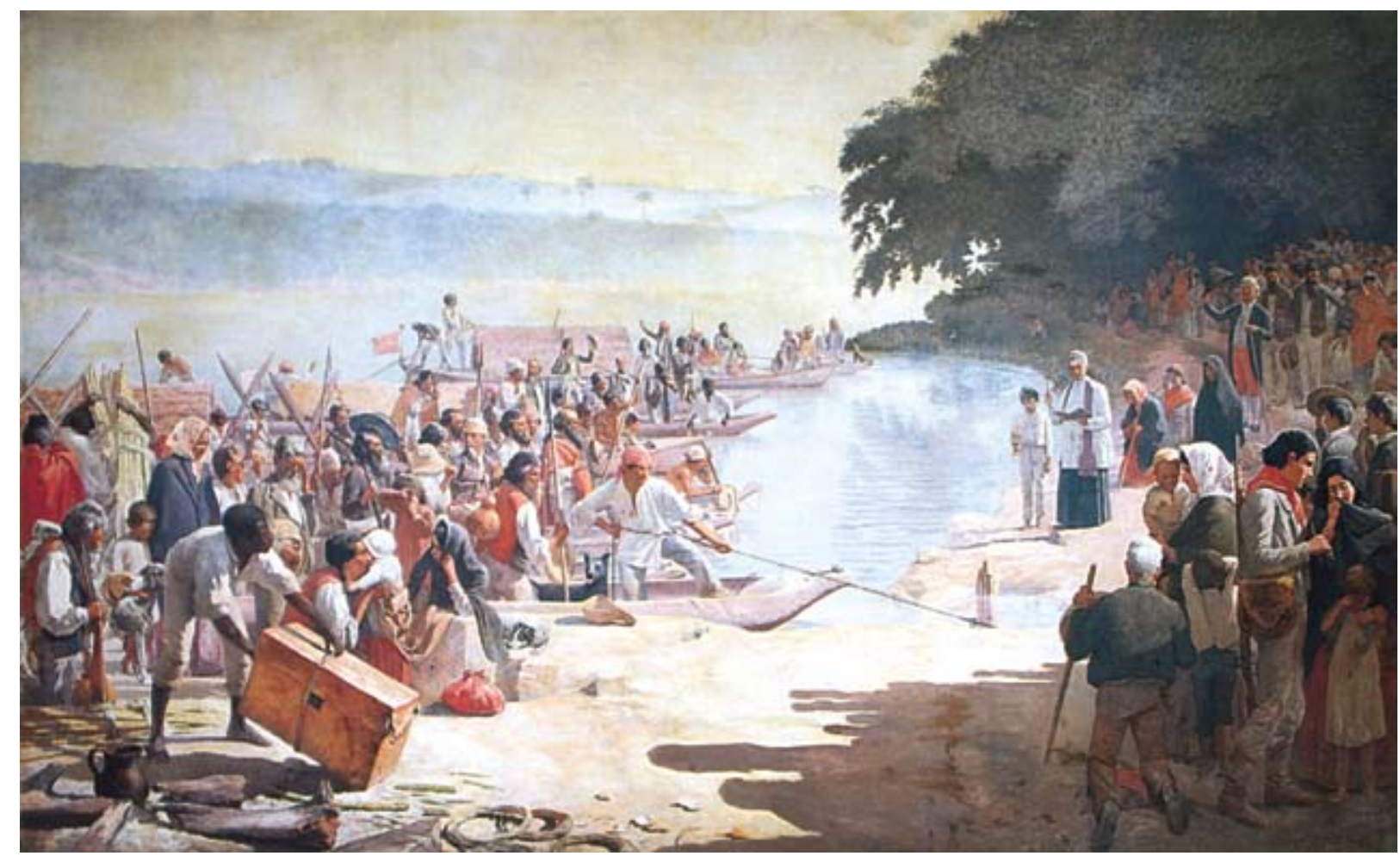

Figura 2 - A partida da Monção de José Ferraz de Almeida Júnior (1 850-1899). Óleo sobre tela, 640 × 390cm. Acervo do Museu Paulista da USP. Fotografia de José Rosael.

Pai Nosso Pequenino

Deus me leve em bom caminho

Sete anjos me acompanha

Sete velas me alumeia

São Francisco é meu padrinho

Santa Maria é minha madrinha

Que me fez a cruz na testa

Nada de mau me persiga

Nem de noite nem de dia

Nem no ponto do meio dia

Nem na hora d'eu deitar

Para sempre, Virgem Maria ${ }^{17}$
17. Ver N. P. de Magalhães e E. de A. Pereira (1989).

18. Cf. Jonas Soares de Souza e Miyoko Makino (2000, p. 52-53).

Aos poucos, o ruído do rio se encorpa, seu curso se empola, em função das grandes pedras que anunciam uma queda d'água. São 46 as cachoeiras que Juzarte afirma ter encontrado no rio Tietê ${ }^{18}$, várias delas representadas nos mapas que compõe o percurso fluvial, como os saltos de Avanhandava e ltapura. Ao lado deles, há indicações de sítios, pousos e diversos varadouros por onde as canoas eram arrastadas por terra para vencer o desnível das cachoeiras (Figuras 3 a 6$)$. 


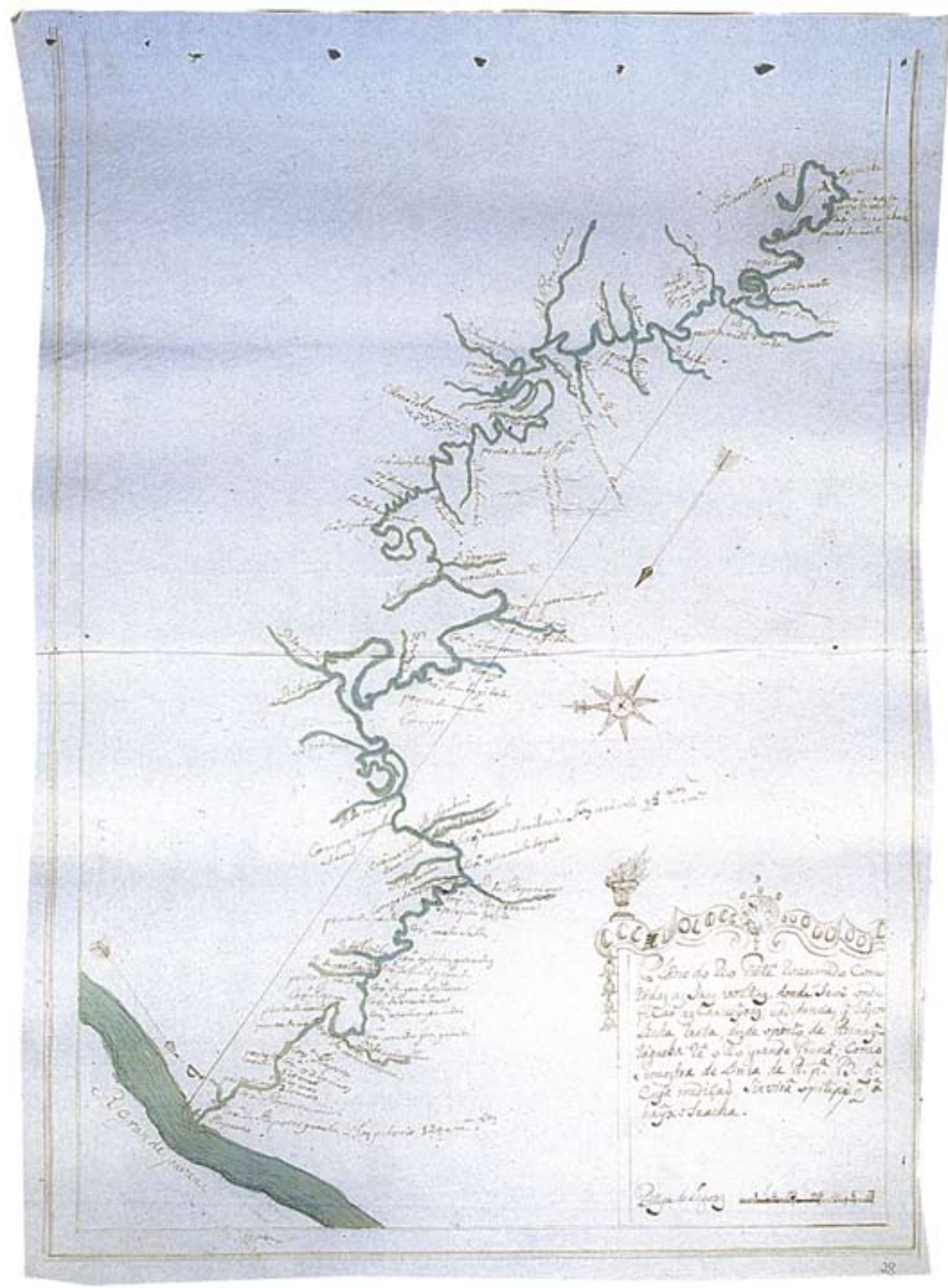

Figura 3 - Teotônio José Juzarte. Plano do Rio Tietê resumido com todas as suas voltas donde se vê onde ficam as cachoeiras e a distancia que há por linha reta desde o porto de Araritaguaba até o rio Grande Paraná...., 1769. Diário da Navegação, 2000, p.395. 


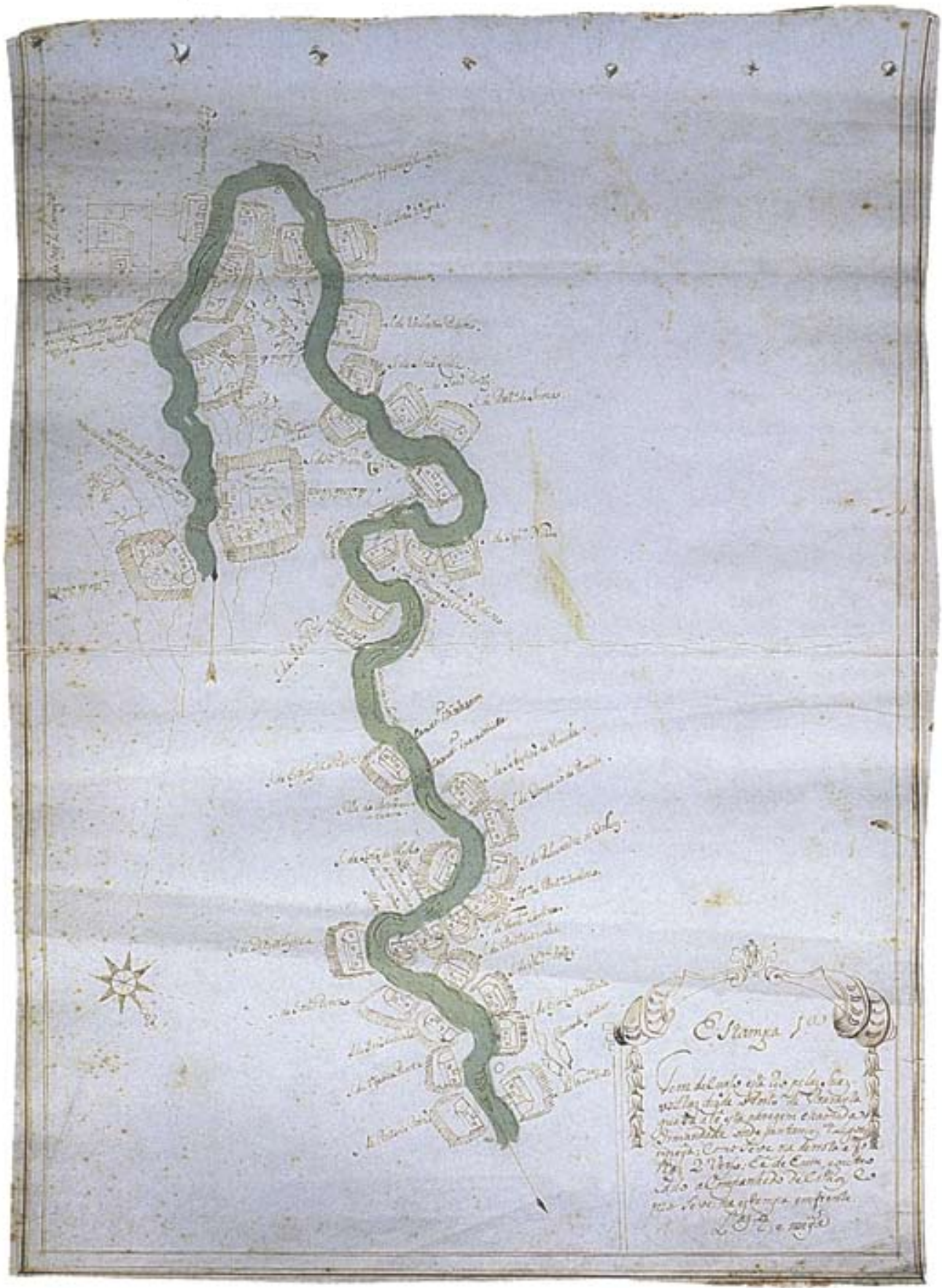

Figura 4 - Teotônio José Juzarte. Folha do mapa de navegação, representando o trecho inicial a partir do porto de Araritaguaba (atual Porto Feliz) até a paragem de Irmandade, figurando e identificado cachoeiras e sítios, 1769. Diário da Navegação, 2000, p.370. 


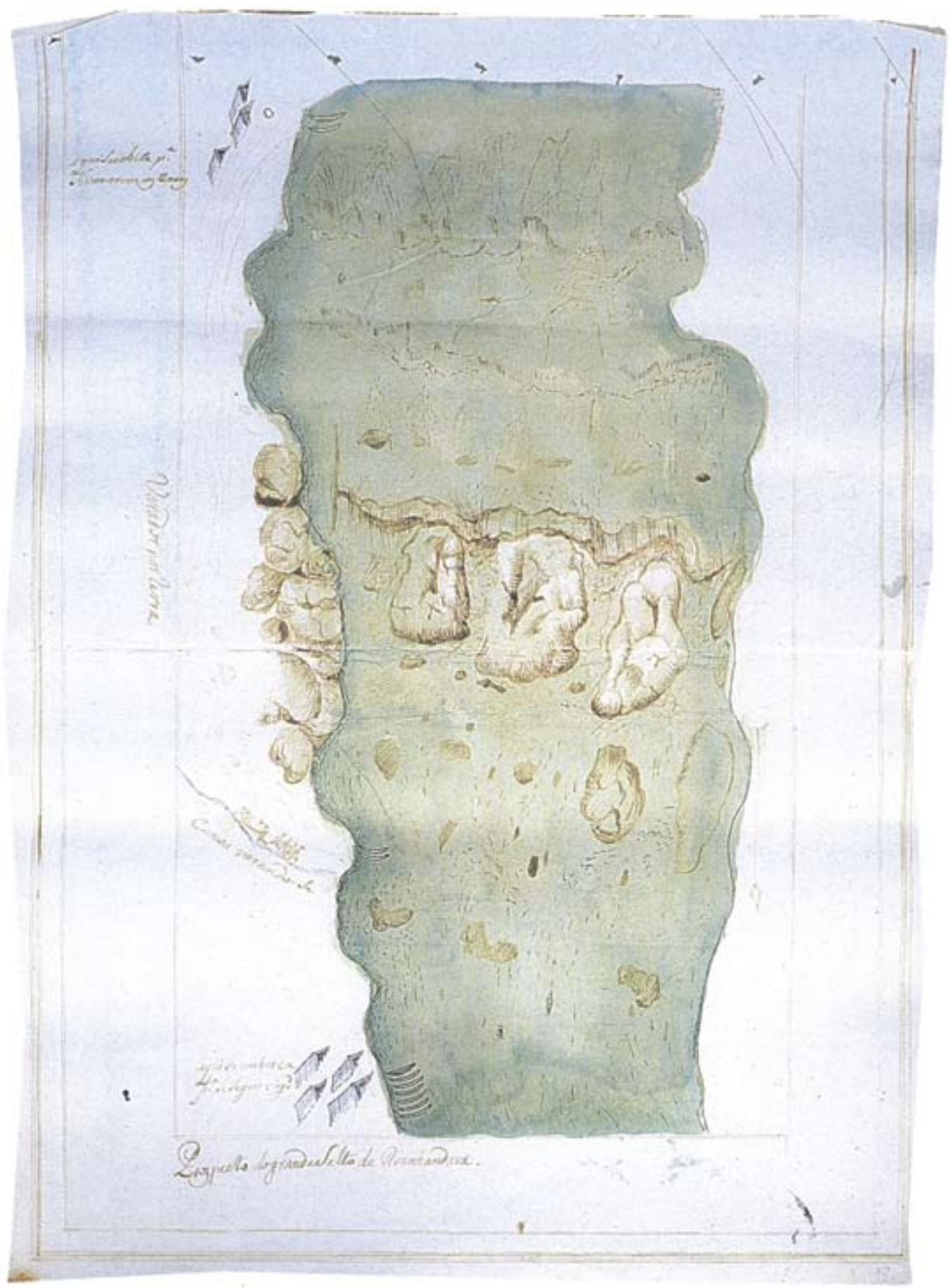

Figura 5 - Teotônio José Juzarte. Prospecto do grande Salto de Avanhandava, situado no rio Tietê, 1769. Diário de Navegação, 2000, p. 385. 


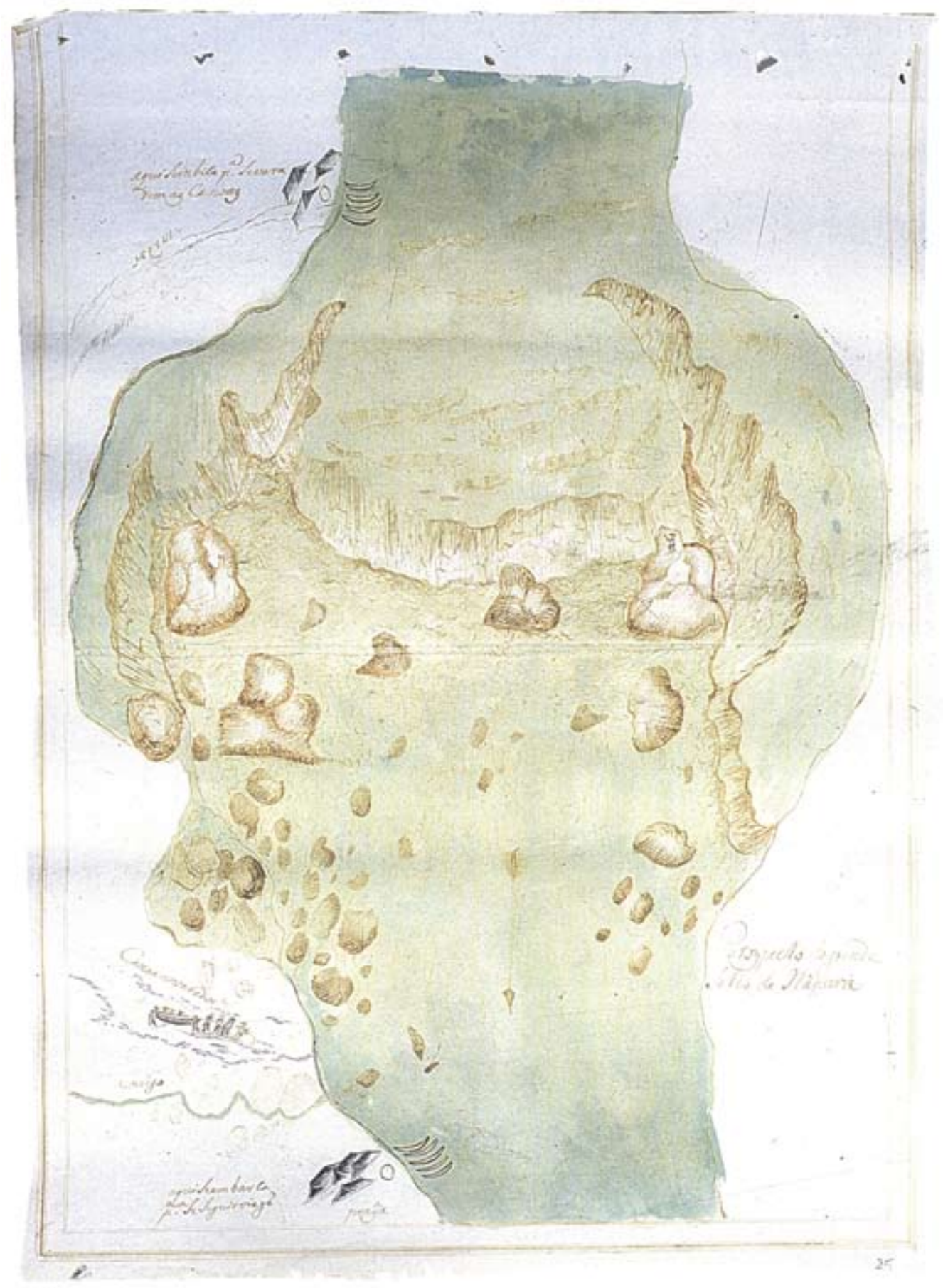

Figura 6 - Teotônio José Juzarte. Prospecto do grande Salto de ltapura, situado no rio Tietê, 1769. Diário de Navegação, 2000, p. 394. 
20. A. de E. Taunay (1931, p. 89).

21. Cf. A. M. Araújo (1964, p. 42).
Ultrapassado o acidente, as canoas retomam seu curso, em aparente tranquilidade, ao som de Matais de Incêndios meu Lindo, ai-lêtlê, vilancico de um dos compositores do Grupo de Mogi, em redução para viola de arame realizada e executada por Gisela Nogueira. Esse instrumento é o mesmo que figura no inventário de Sebastião Pais de Barros e foi construído, especialmente para Gisela, como réplica de um original do século XVIII encontrado em Tiradentes, MG. Pertence à família da guitarra barroca, possui duplos e triplos cursos ( 12 cordas). Simplificado no século XIX (1 0 cordas), será amplamente utilizado pelos tropeiros e ainda hoje permanece, nas regiões rurais, com o nome de viola caipira.

Enquanto realizávamos a trilha, foi localizado, no acervo do Museu Paulista, um grande armário repleto de instrumentos. Entre eles, encontramos algumas violas e rabecas rústicas nos moldes das que eram usadas no século XVIII e que foram expostas na chamada Sala do Sertão, na qual foi instalada a trilha.

\section{Viagem pelo Paraná e lguatemi}

Segundo o diário de Juzarte, à medida que a monção penetra no Paraná, a presença indígena torna-se mais frequente. As dificuldades aumentam, causadas por neblinas, redemoinhos (Figura 7), chuvas, picadas de insetos e cobras, doenças, mortes. Neste ponto, a trilha se torna mais escura, o rio se cala, ouvem-se, ao longe, as flautas dos índios Bororo ${ }^{19}$ e uma atmosfera noturna, propiciada por ruídos de insetos e batráquios, emoldura o benzimento contra todos os males que o bandeirante João Batista Vitoriano levava consigo no sertão:

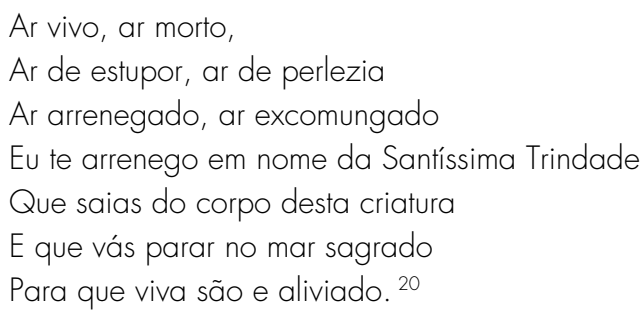

A presença indígena se faz mais próxima e, segundo Juzarte, todos se encomendam à Virgem, fato representado, na trilha, pela recriação de trecho de uma salve-rainha popular, recolhido no estado de São Paulo, no qual são evidentes os vestígios do cantochão gregoriano, tanto na linha melódica como na forma de entoá-la:

Salvi Rainha, mãe de misericorde

Vida, doçura, mãe desperância nossa.

Salvi o vós salvi os degredados filhos de Eva

Por vós suspiramo, gemeno e chorano

Neste vali de lágrimas $[\ldots]^{21}$

A prece é interrompida pela cadência marcante dos índios Kaiapó, 


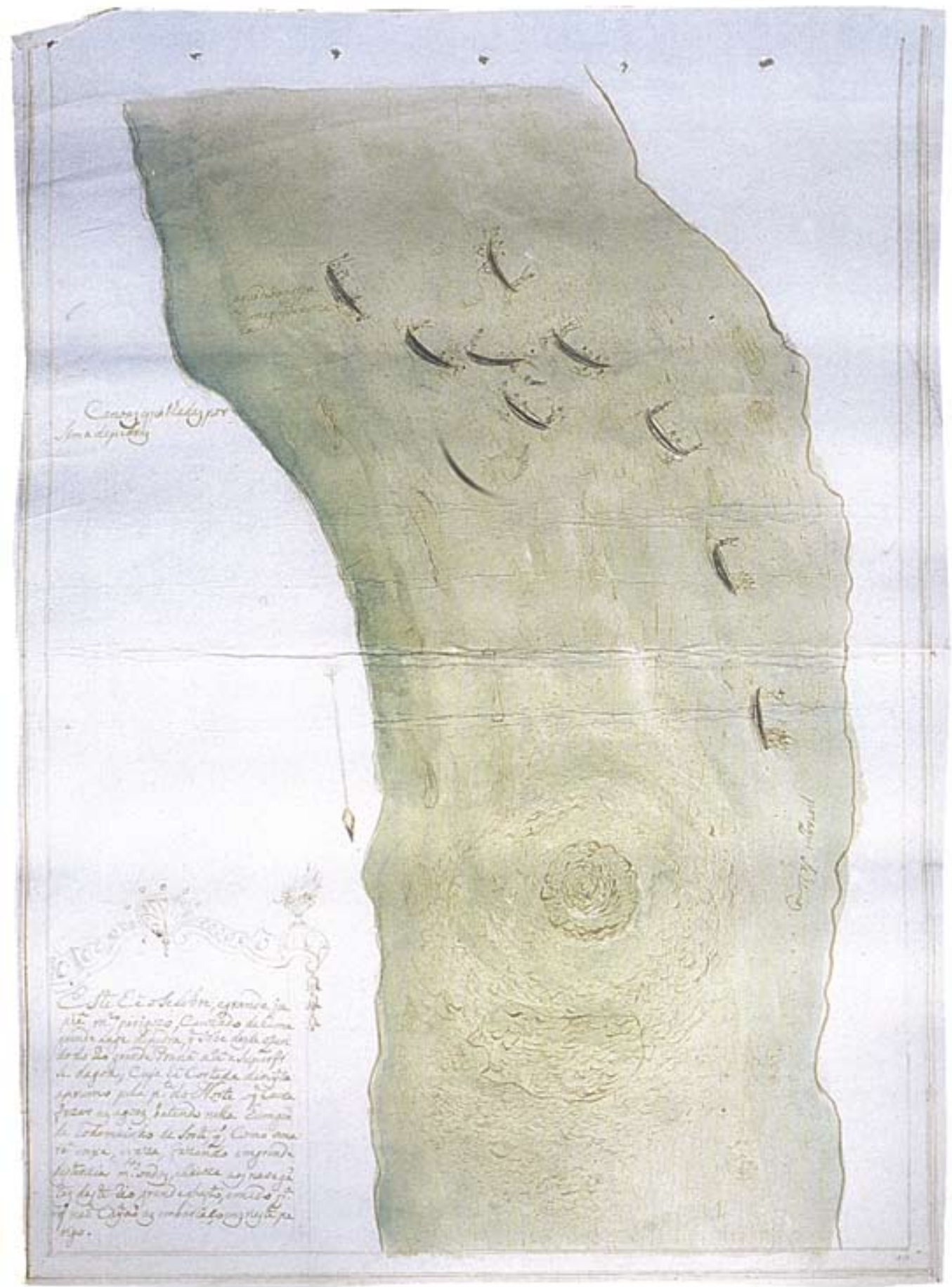

Figura 7 - Teotônio José Juzarte. Este é o célebre e grande Jupiau, muito perigoso, causado de uma grande lage de pedra, que sobe desde o fundo do rio Grande Paraná até a superfície da água (...) o que causa fazer as águas batendo nela um grande rodamoinho..., 1769. Diário da Navegação, 2000, p. 397. 
22. Ouvir Gustaaf Verswijver (1989); R. Canzio (1989).

23. Cf. A. Caufriez (1998, p. 246-247). em trecho da cerimônia Bep, relativa à imposição dos nomes aos adolescentes, aqui escolhida como representação de sua afirmação como povos indígenas ameaçados. A eles se juntam, em colagem, outros trechos de cantos Kaiapó e choros rituais Bororo ${ }^{22}$, em atmosfera opressiva, uma vez que a reação indígena provocou grande pânico e alguns embates mortais, sob terríveis tempestades, o que reduziu, cada vez mais, o número de integrantes da monção, abatidos pela fome e dizimados pela peste.

A sessão culmina com o ruído de trovões seguidos de forte chuva que lava tudo.

\section{Coda}

Passada a tempestade, o rio reaparece, calmo, e, sobre ele, uma canoa conduz a memória de uma cantiga, acompanhada à viola, que remete a tradições milenares. Sete estrelas rondadoras refere-se ao setestrelo, termo pelo qual era conhecida, no XVIII, a constelação das Plêiades, formada pelas sete filhas de Atlas, condenado a carregar em seus ombros a abóbada celeste:

\author{
Sete estrelas rondadoras \\ Contai-las a quem namora, \\ Acabai a vossa ronda \\ Queu quero rondar agora. \\ Sete estrelas rondadoras \\ Contai-las a quem quer bem \\ Acabai a vossa ronda \\ Que eu quero rondar também. ${ }^{23}$
}

Assim, uma vez satisfeitos conceitos históricos de tempo e espaço la cantiga foi extraída de uma coleção de peças tradicionais portuguesas, muitas das quais pertencem também à tradição brasileira e paulista) e estéticos (Gisela harmonizou a peça, enfatizando marcas do Fandango do Sudeste), encerramos nosso trabalho sob o olhar de Atlas e de suas filhas. $\bigcirc$ que poderia ser mais auspicioso, em se tratando da trilha sonora de uma exposição cartográfica?

\section{REFERÊNCIAS}

ALVARENGA, O. Música popular brasileira. Porto Alegre: Globo, 1960.

ANDRADE, M. de. Danças dramáticas do Brasil, 1. São Paulo: Martins, 1959.

ARAÚJO, A. M. Araújo. Folclore Nacional, 2. São Paulo: Melhoramentos, 1964.

CANZIO, R. (Org.).The Bororo World of Sound. CD. Paris: Unesco; Auvidis, 1989. 
CAUFRIEZ, A. Romances du Trás-os-Montes. Lisbonne; Paris: Centre Culturel Calouste Gulbenkian, 1998.

FERREIRA, Manuel Pedro. As cantigas de Martim Codax. Edição fac-similar e transcrição das cantigas. Lisboa: Unisys; Imprensa Nacional-Casa da Moeda, 1986.

GAVALDÁ, M. Q. (Org.). Cancionero Musical de La Colombina. Barcelona: Consejo Superior de Investigaciones Cientificas; Instituto Español de Musicologia, 1971.

KIEFFER, A. M. Cancioneiro da Imigração a partir de Memória Viva Guarani. CD-livro. São Paulo: Akron, 2004.

KUPPER, Leo (comp.). Aerosons. Bruxelas: Studio de Recerches et de Structurations Électroniques-Auditives, 1982.

MAGAlHÃeS, N. P. de; PEREIRA, E. de A. Assim se benze em Minas Gerais. Juiz de Fora: EDUFJ; Mazza, 1989.

SOUZA, Jonas Soares de; MAKINO, Miyoko (Org.). Diário de Navegação. São Paulo: Edusp, 2.000 .

TAUNAY, A. E. História da Vila de São Paulo no século XVIII. São Paulo: Imprensa Oficial, 1931.

TRINDADE, J.; CASTAGNA, P. Música pré-barroca luso-americana: o grupo de Mogi das Cruzes. Revista Eletrônica de Musicologia, Curitiba. Disponível em: <http:www.rem.ufpr.br/REMvol1.2/ Mogi.html>.

VERSWIJVER, Gustaaf (Org). Brésil Central: chants et danses des Indiens Kaiapó: gravações de René Fuerst e George Love (1966), Pascal Rosseels (1974-1975) e Gustaaf Verswijver (1978-1981). CD. Genève: Archives internationales de musique populaire, 1989.

Artigo apresentado em 8/2008. Aprovado em 12/2008. 